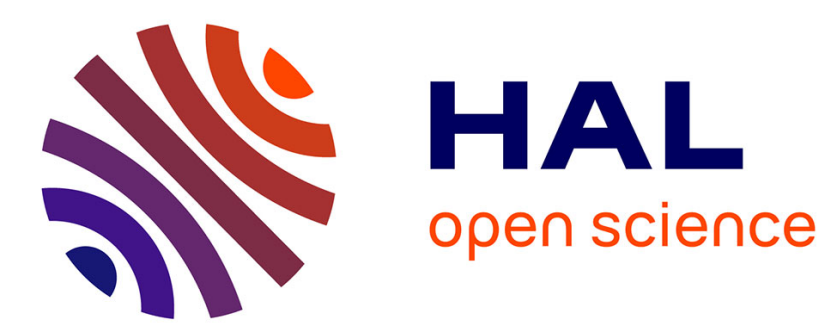

\title{
Avalanche robustness of SiC Schottky diode
}

\author{
Ilyas Dchar, Cyril Buttay, Hervé Morel
}

\section{To cite this version:}

Ilyas Dchar, Cyril Buttay, Hervé Morel. Avalanche robustness of SiC Schottky diode. Microelectronics Reliability, 2016, 10.1016/j.microrel.2016.07.086 . hal-01373039

\section{HAL Id: hal-01373039 \\ https://hal.science/hal-01373039}

Submitted on 28 Sep 2016

HAL is a multi-disciplinary open access archive for the deposit and dissemination of scientific research documents, whether they are published or not. The documents may come from teaching and research institutions in France or abroad, or from public or private research centers.
L'archive ouverte pluridisciplinaire HAL, est destinée au dépôt et à la diffusion de documents scientifiques de niveau recherche, publiés ou non, émanant des établissements d'enseignement et de recherche français ou étrangers, des laboratoires publics ou privés. 


\title{
Avalanche Robustness of SiC Schottky Diode
}

\author{
Ilyas DCHAR ${ }^{\mathrm{a}}$, Cyril BUTTAY ${ }^{\mathrm{b}, *}$, Hervé MOREL ${ }^{\mathrm{b}}$.
}

\author{
a Power Electronics, SuperGrid Institute, Villeurbanne, France. \\ ${ }^{b}$ Université de Lyon, CNRS, INSA-Lyon, Laboratoire AMPĖRE, UMR 5005, F-69621, Villeurbanne, France
}

\begin{abstract}
Reliability is one of the key issues for the application of Silicon carbide (SiC) diode in high power conversion systems. For instance, in high voltage direct current (HVDC) converters, the devices can be submitted to high voltage transients which yield to avalanche. This paper presents the experimental evaluation of SiC diodes submitted to avalanche, and shows that the energy dissipation in the device can increase quickly and will not be uniformly distributed across the surface of the device. It has been observed that failure occurs at a fairly low energy level $\quad<0.3$ $J / \mathrm{cm}^{2}$ ), on the edge of the die, where the electrical field intensity is the greatest. The failure results in the collapse of the voltage across the diode (short-circuit failure mode). If a large current is maintained through the diode after its failure, then the damage site is enlarged, masking the initial failure spot, and eventually resulting in a destruction of the device and an open circuit.
\end{abstract}

\section{Introduction}

Silicon carbide Schottky diodes are attractive devices to replace silicon rectifiers in several applications as they offer many superior properties (High voltage capability, very low switching losses and little stored charge). In some applications such as HVDC converters, many diodes are used in series to increase the blocking voltage. Generally, homogeneous voltage distribution has to be forced: in blocking-state by using parallel resistors; during commutation using parallel RC [1]. Nevertheless, in some cases, the voltage may not divide equally across the series string of diodes. A transient of sufficient amplitude will drive the voltage across one or more diodes into the breakdown region.

In general, SiC Schottky diodes suffer from their very limited avalanche breakdown stability due to the avalanche current filamentation at the Schottky interface or the edge termination [2]. The avalanche test is an essential reliability standard test for high-power devices as this phenomenon may happen in every switching converter or inverter during transient operating modes. The test allows to obtain data about the capability of $\mathrm{SiC}$

* Corresponding author: cyril.buttay@insa-lyon.fr Tel: 00.33.(0)6.88.03.02.52
Schottky diodes under avalanche operation. They provide key information about how to design a Schottky diode, which can limit the effects of avalanche on the devices and provide protection for the application.

Destructive failure under avalanche operation has been studied extensively for many power devices such as MOSFETs and IGBTs [3], [4] but more recent devices such as SiC Schottky diodes have not yet been investigated as much. Zhang et al. have presented a failure mechanism analysis for Schottky diode [5]. It has been reported that the avalanche breakdown is considered as the main catastrophic failure mechanism of Schottky diodes. As in any semiconductor or metal/semiconductor junction, under excessive electric field, the thermally generated electrons and holes get enough kinetic energy to knock on atoms, which then generate more electronhole pairs within the diode. This results in high reverse current generated within the device. As a consequence, the power dissipation increases in a localized spot which then destroys the device thermally [6].

This paper proposes a thorough experimental tests of the performance of commercially available SiC Schottky diode under avalanche conditions. The remainder of this study is organized as follows: the avalanche tester and the operating principle is presented in Section 2. Section 3 describes the results concerning the reliability of tested SiC Schottky diode under avalanche conditions. Section 4 shows some discussions about the failure mechanisms 
that limit the device reliability. Finally conclusions are given in Section 5.

\section{Experimental setup}

\subsection{Description of the bench}

The circuit diagram of the experimental setup is shown in Fig. 1. It includes the following parts: a high voltage power supply $(0 \ldots 3 \mathrm{kV} \mathrm{DC})$ charges up a film capacitor $\mathrm{C}(1250 \mu \mathrm{F}, 3 \mathrm{kV})$. The stored energy is used to produce the avalanche conditions.

An IGBT controls the duration of the high voltage pulse applied to the device under test (DUT) and a resistor is used to set the current during the avalanche [7]. The control IGBT can be switched off immediately after the failure of the DUT to avoid its explosion. For safety reasons, the circuit is placed in a closed system, visible in Fig. 2, which includes the high voltage power supply, the capacitors, the test zone, and a control panel (other features are included but not used in this article, such as over-current detection, active current limitation, etc.). An interlocking mechanism, connected to high voltage contactors, prevents any accidental contact with high voltage. The implementation of these safety systems required in a fairly long cabling between the capacitors and the test zone, resulting in a total stray inductance estimated at $10 \mu \mathrm{H}$.

This test circuit is fairly different from the commonly used (and described in a JEDEC standard [8]) "Unclampled Inductive Switching" (UIS). Here, the energy tank is a capacitor (instead of an inductor in the case of UIS). Using a capacitor is less practical, as it requires a high voltage power supply and an accurate control of the voltage. However, the same capacitor bank can also be used for short circuit tests (not described in this article). This makes the test bench more versatile, which is why we chose this solution.

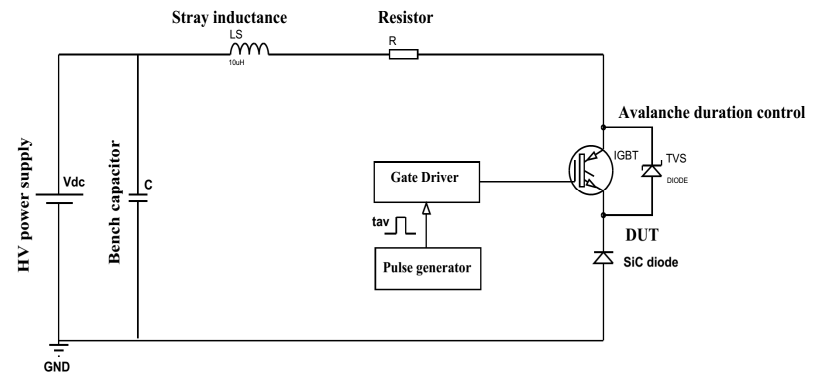

Fig. 1. Schematic of avalanche test circuit for SiC Schottky diode.

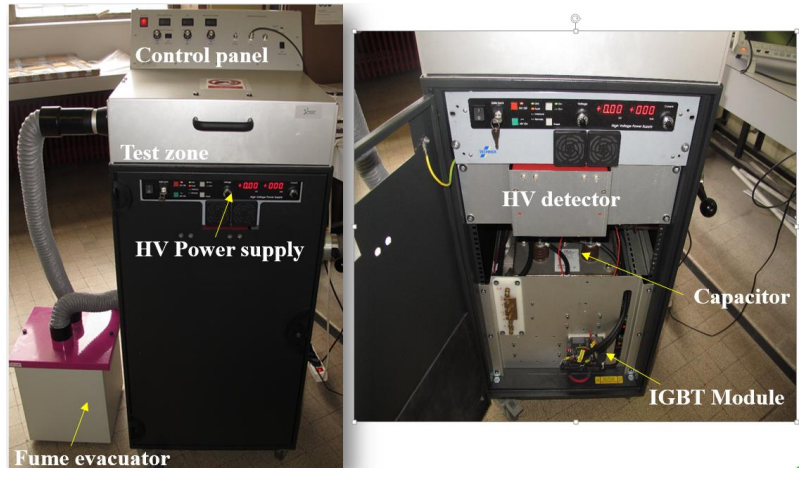

Fig. 2. Picture of the experimental setup using the power circuit in Fig. 1

The main specifications of the experimental setup are summarized in the following table:

\begin{tabular}{lc}
\hline \multicolumn{1}{c}{ Characteristic } & Value \\
\hline Maximum voltage & $3 \mathrm{kV}$ \\
Maximum current & $500 \mathrm{~A}$ \\
R resistor & 10 or $50 \Omega$ \\
C capacitor & $1250 \mu \mathrm{F}$ \\
Stray inductance & $10 \mu \mathrm{H}$ \\
Avalanche duration control & HITACHI MBM500E33E2 \\
& $3.3 \mathrm{kV}, 500 \mathrm{~A}$ \\
\hline Table 1. The main specification of the experimental setup
\end{tabular}

\subsection{Test Protocol}

In this paper, we investigate a $1200 \mathrm{~V}$ SiC Diode (C4D20120A from Wolfspeed). The devices under test are single chip in TO220 package, the rated characteristics of this devices are shown in Table 2.

\begin{tabular}{ccccc}
\hline Power device & $\begin{array}{c}\text { VRRM } \\
(\mathrm{V})\end{array}$ & $\begin{array}{c}\text { IF } \\
(\mathrm{A})\end{array}$ & $\begin{array}{c}\text { Die size } \\
\left(\mathrm{mm}^{2}\right)\end{array}$ \\
\hline DUT & SiC Diode & 1200 & 20 & $3.1 * 3.1$ \\
\hline
\end{tabular}

Table 2 .Rated characteristics of tested SiC Schottky Diode

Avalanche tests are performed with a current limiting resistor of either 10 or 50 ohms. In each configuration, an avalanche duration is fixed (a different one for each device tested). Then, the DC voltage is gradually increased from a low value (where the device is able to sustain the avalanche conditions) up to the failure. Before failure, the device can survive many voltage pulses. Once failed, the device is no longer able to sustain the full DC voltage. The energy leading to the device failure is determined by measuring the reverse current and voltage using respectively a Pearson current monitor model 4997 and a high voltage probe (PHV 662-L) from PMK. This energy is called the critical energy $E_{C}$, which is an essential feature of robustness to SiC Schottky diode. It can be calculated as the time integral of the product of the reverse voltage $V_{d}$ and the reverse current $I_{d}$ (see.Fig.3).

$E_{c}=\int_{t_{1}}^{t_{2}} V_{d}(t) \cdot I_{d}(t) d t$ 
Fig. 3 shows the typical set of waveforms obtained under avalanche operation, when a device fails: $V_{G E}$ is the gate signal applied to the control IGBT (red); $I_{d}$ is the reverse current in the DUT (green); $V_{d}$ is the reverse voltage measured across the DUT (blue) and $E$ refers to the energy dissipation of the device (gold). As it can be seen, $V_{d}$ is initially equal to $V_{i} \approx 0$ when the IGBT is off. Once the pulse is applied through the $\operatorname{IGBT}\left(t_{1} \leq t \leq t_{3}\right)$, and if the DC voltage exceeds the breakdown voltage $\left(V_{B R}<V_{D C}\right)$ of the diode, some current flows through the diode. At this stage, the avalanche current is limited by the resistor $\left(\mathrm{I}=\left(\mathrm{V}_{\mathrm{DC}}-\mathrm{V}_{\mathrm{BR}}\right) / \mathrm{R}\right)$ to a few amperes. After failure of the devices ( $t_{2}$ in Fig. 3), the voltage across the DUT collapses to almost zero, and the current increases dramatically to $\mathrm{I}=\mathrm{V}_{\mathrm{DC}} / \mathrm{R}$.

If no current limiting resistor was used, the power dissipated by the DUT after failure would be much higher, resulting in its destruction, even if the control IGBT is turned off rapidly after $t_{2}$. Consequently, the damage would be extended through all the surface of the $\mathrm{SiC}$ chip hiding the actual origin of the device failure.

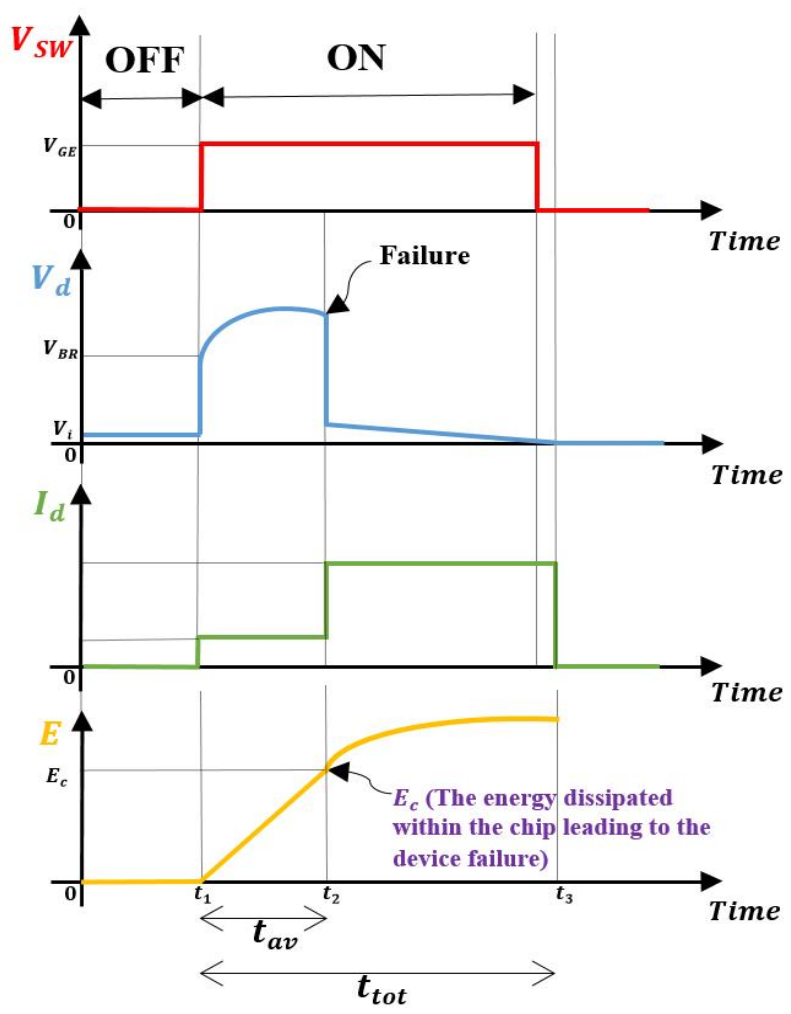

Fig. 3. Typical waveforms under avalanche operation.

\subsection{Failure analysis}

To analyse the location and extend of the failure on the die, a failure analysis was performed on several failed devices. We removed the plastic molding from a few parts that were destroyed in course of the tests using mixtures of higher ratio of concentrated sulfuric acid along with nitric acid (Mixtures of acid are more efficient to dissolve plastic molded components than using concentrated acids alone [9]). In some cases, the component was destroyed in the avalanche test and no decapsulation was possible. The decapping process parameters are summarized in the following table:

\begin{tabular}{|c|c|c|c|c|}
\hline \multicolumn{2}{|c|}{$\begin{array}{c}\text { Acid } \\
\text { mixture } \\
(w t \%)\end{array}$} & \multirow[t]{2}{*}{$\begin{array}{c}\text { Acid } \\
\text { temperature } \\
\left({ }^{\circ} \mathrm{C}\right)\end{array}$} & \multirow[t]{2}{*}{$\begin{array}{c}\text { Acid } \\
\text { volume } \\
\text { (ml) }\end{array}$} & \multirow[t]{2}{*}{$\begin{array}{c}\text { Flow } \\
\text { rate } \\
\text { (ml/min) }\end{array}$} \\
\hline $\begin{array}{l}\text { Acid } \\
\text { nitric }\end{array}$ & $\begin{array}{l}\text { Acid } \\
\text { sulf. }\end{array}$ & & & \\
\hline 20 & 80 & 200 & 24 & 6 \\
\hline
\end{tabular}

Table 3. Decapping process parameters

After the decapping, the samples were rinced in acetone, and observed using an optical microscope.

\section{Experimental results}

\subsection{Avalanche Robustness}

The obtained results, concerning the robustness in avalanche for DUT at $25{ }^{\circ} \mathrm{C}$ ambient temperature are shown in Fig.4. In this figure, each point is the result of a destructive avalanche test on a given device, with on the $\mathrm{Y}$ axis the critical energy (measured between $t_{1}$ and $t_{2}$ in Fig. 3) and on the $X$ axis the avalanche duration before failure $\left(\mathrm{t}_{\mathrm{av}}\right)$. As illustrated in Fig.4, a large dispersion of the critical energies is observed by varying the avalanche duration, and no clear trend can be found. The average of the critical energy is $0.877 \mathrm{~J}$.

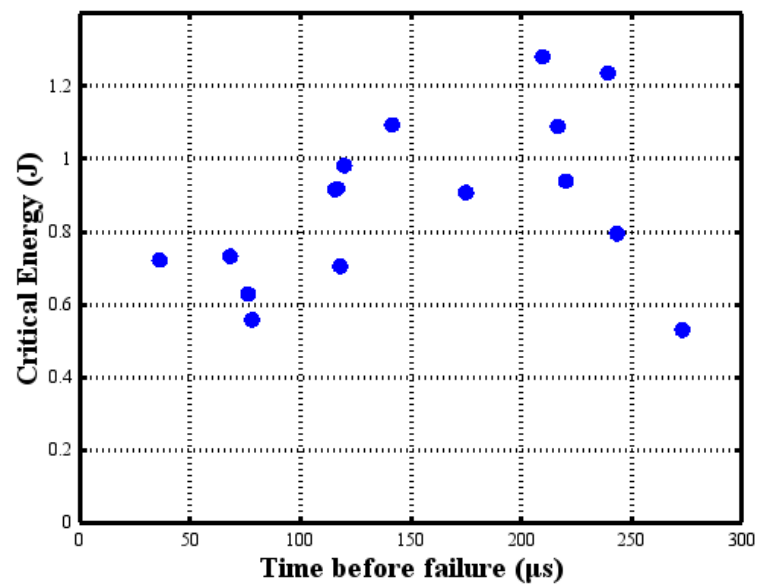

Fig. 4. Robustness in avalanche conditions of C4D20120A SiC Schottky diode.

Using the same dataset, we analyzed the breakdown voltage of the diodes. These diodes were purchased in several batches, maximizing the chances to mix devices produced from different wafers. The breakdown voltage is measured at $t_{1}$ (Fig. 3), i.e. at the very beginning of the avalanche pulse, so that self-heating can be considered negligible ( $\mathrm{V}_{\mathrm{BR}}$ has a positive temperature coefficient). Fig. 5 presents the distribution of breakdown voltages across the diode population. It appears that the actual breakdown is much higher $(>1600 \mathrm{~V})$ than the rated voltage of the diodes $(1200 \mathrm{~V})$. There is a relatively large scattering of the $\mathrm{V}_{\mathrm{BR}}$ values (from 1600 to $1830 \mathrm{~V}$ from a device to another), but this is not uncommon with breakdown voltage. Most devices have a breakdown voltage of around $1800 \mathrm{~V}$. In Fig. 6, we plotted the critical energy as a function of the breakdown voltage. 
Here again, no clear trend can be extracted from the dataset.

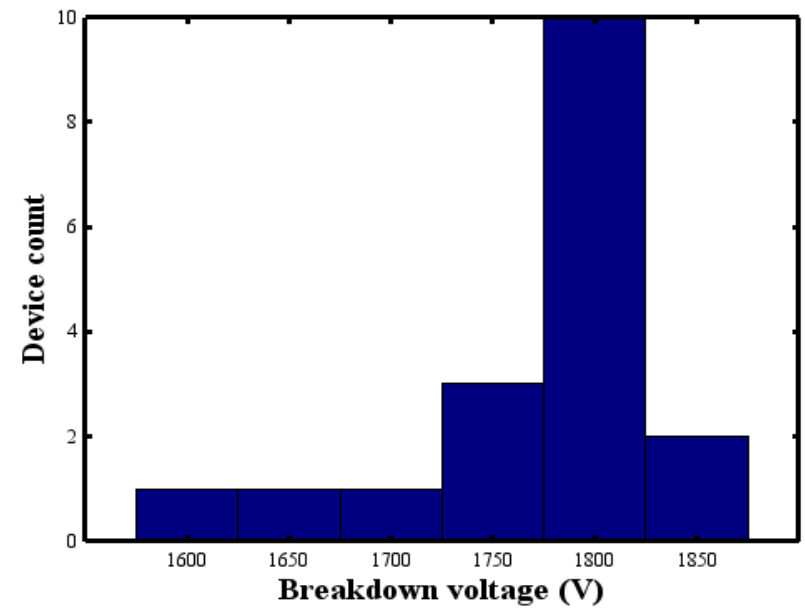

Fig. 5. Number of device failed as a function of the breakdown voltage

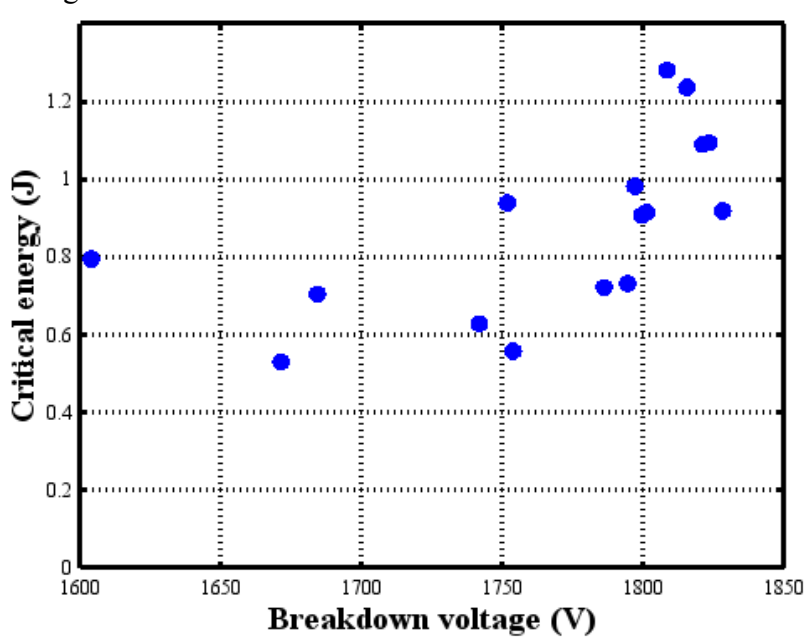

Fig. 6. Critical energy as a function of the breakdown voltage

Finally, a plot of the average power as a function of pulse duration is given in Fig. 7. Average of critical power is calculated as the critical energy divided by the time before failure $\left(\mathrm{t}_{\mathrm{av}}\right)$. Although it is basically the same data as plotted in Fig. 4, a decreasing trend is much more obvious here. The red line in Fig. 7 gives the power corresponding to an energy of $0.877 \mathrm{~J}$ (the average of the critical energies measurements), for pulse durations ranging from 50 to $300 \mu \mathrm{s}$. It fits the data relatively well, indicating that the hypothesis of a constant power dissipation for short pulse durations (less than $300 \mu \mathrm{s}$ ) is acceptable.

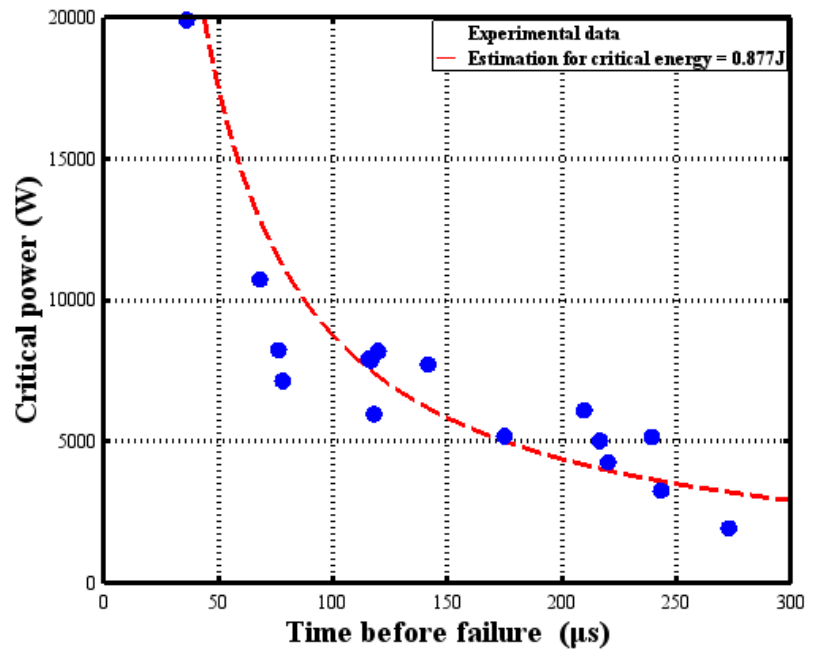

Fig. 7. Critical power as a function of the avalanche duration

Fig. 8 shows the waveforms (current and voltage) captured during an avalanche test. Once the voltage across the DUT is high enough, the avalanche phenomenon starts $(\mathrm{t}=30 \mu \mathrm{s})$. A current begins to flow through the DUT, and is limited by the resistor (see circuit diagram in Fig. 1). The DUT temperature rises because of high power dissipation, resulting in an increase of the breakdown voltage of the DUT, because of the reduction in the ionization coefficient of $\mathrm{SiC}$ [10]. As a consequence, the voltage drop across the resistor decreases, resulting in further limitation of the current. In these test conditions, failure between the terminals of the DUT can be observed at $\mathrm{t}=90 \mu \mathrm{s}$, while the actual avalanche starts at $\mathrm{t}=30 \mu \mathrm{s}$ (when some current starts to flow through the diode). The failure corresponds to a sudden collapse in the voltage across the diode, indicating that the device is no longer able to sustain its breakdown voltage. After this voltage collapse, the current is only limited by resistor $\mathrm{R}$ (here $10 \mathrm{ohms}$ ) and the stray inductance of the test system, hence a dramatic increase. Shortly after the failure $(\mathrm{t}=100 \mu \mathrm{s})$, the control IGBT is turned-off, preventing further damage to the DUT. As a result, the DUT has no longer any blocking capability, a condition we call here "failure to short-circuit". The energy dissipated by the DUT before failure (the critical energy) is equal to $0.73 \mathrm{~J}$. In order to analyze the effect of this energy on the device destruction, we have removed the plastic molding from the tested device, following the procedure described above. The image of the decapsulated DUT is shown in Fig. 9. As it can be seen, a clear defect is located in the diode's periphery, near the edge of the device. This defect appears to propagate in the $\mathrm{SiC}$, (it is not just located on the surface of the die), and no other area of the die seems damaged (no indication of melting of the metal layer, for example). This indicates that during avalanche, the energy was concentrated in a single spot rather than distributed evenly over the surface of the die. 


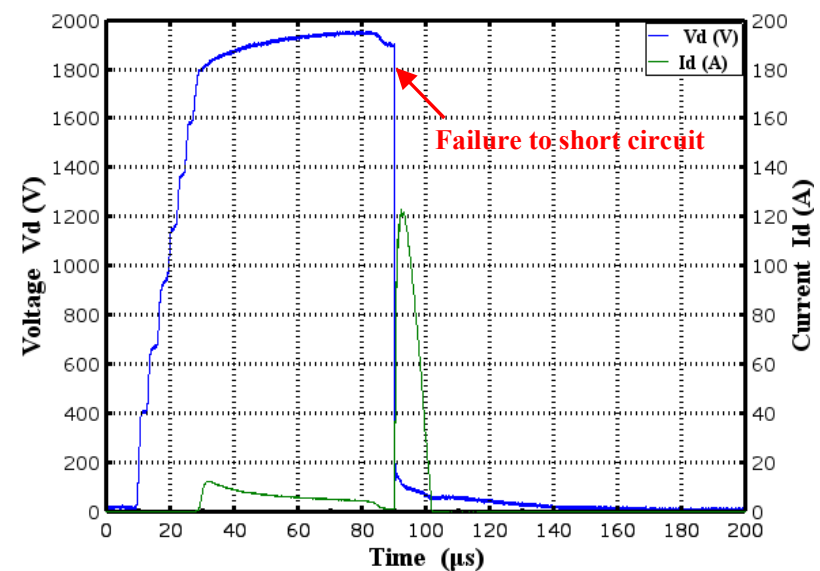

Fig. 8. Measured reverse voltage and current across the diode under avalanche conditions. $\mathrm{T}_{\mathrm{c}}=25^{\circ} \mathrm{C}$; $\mathrm{tav}=68.57 \mu \mathrm{s} ; \mathrm{E}_{\mathrm{c}}=0.73 \mathrm{~J}$; $\mathrm{V} \mathrm{BR}=1800 \mathrm{~V}$.

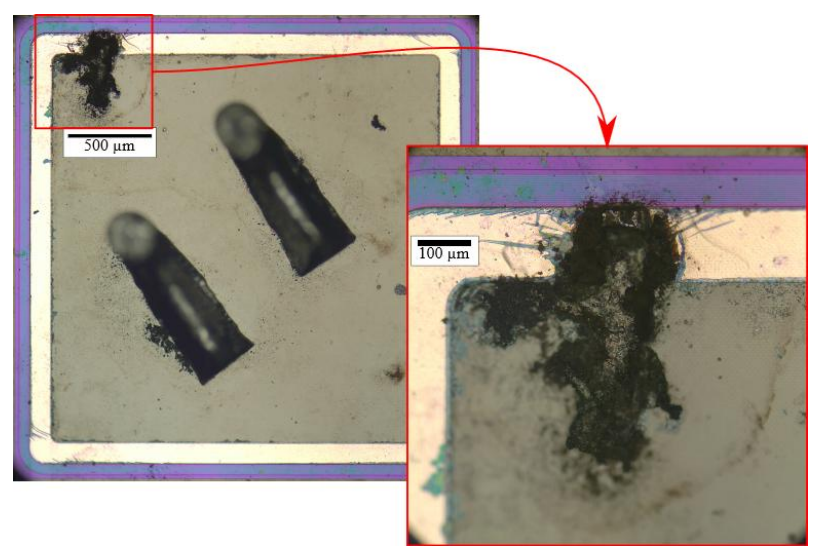

Fig. 9. Damaged of SiC Schottky die for DUT after a destructive avalanche test with $\mathrm{tav}_{\mathrm{av}}=68.57 \mu \mathrm{s} ; \mathrm{E}_{\mathrm{c}}=0.73 \mathrm{~J} ; \mathrm{V}_{\mathrm{BR}}=1800 \mathrm{~V}$.

The same findings can be associated with most DUTs, and another example is given in Fig. 10 and 11. The damage remains of small size, located near to the guard rings, where the electric field is expected to be the highest. Failure to short-circuit is always observed.

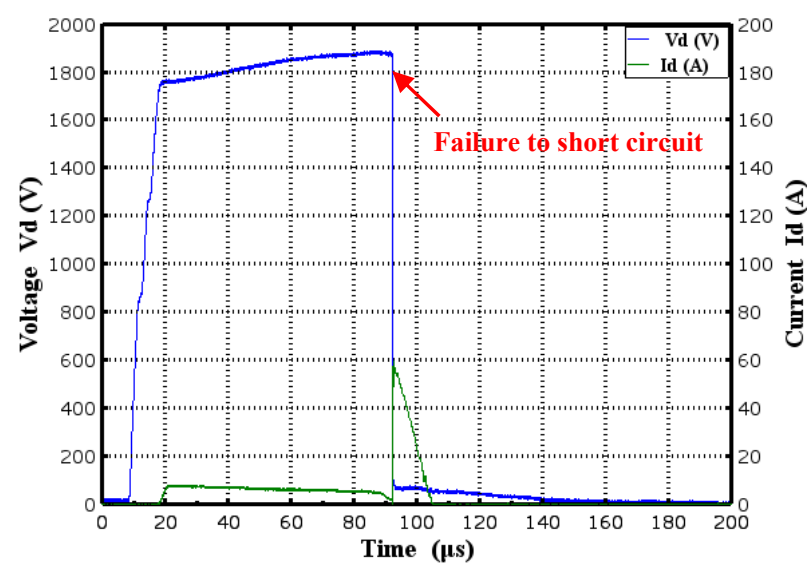

Fig. 10. Measured reverse voltage and current across the diode under avalanche conditions. $\mathrm{Tc}=25^{\circ} \mathrm{C} ; \mathrm{tav}=78.57 \mu \mathrm{s} ; \mathrm{E}_{\mathrm{c}}=0.55 \mathrm{~J}$; $\mathrm{V}_{\mathrm{BR}}=1750 \mathrm{~V}$.

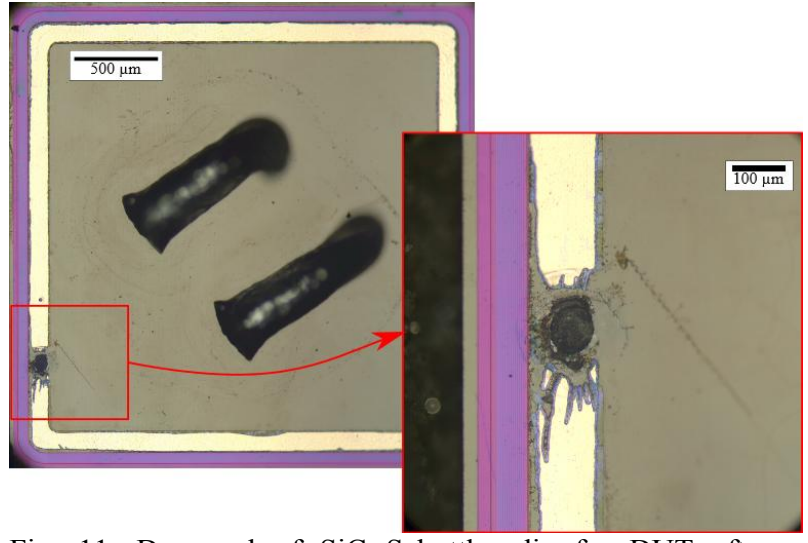

Fig. 11. Damaged of SiC Schottky die for DUT after a destructive avalanche test with $\operatorname{tav}_{a}=78.57 \mu \mathrm{s} ; \mathrm{E}_{\mathrm{c}}=0.55 \mathrm{~J}$; $\mathrm{V}_{\mathrm{BR}}=1750 \mathrm{~V}$.

If the control switch is not turned off immediately after failure, the outcome is quite different: after the voltage collapses across the diode, the current increases dramatically, resulting in a large power dissipation. The originally small damage spread rapidly across the die. The package is no longer able to withstand the mechanical stress and explodes. Fig. 12 shows such an example of "un-controlled" test conditions. After the device failed for a critical energy of $1.2 \mathrm{~J}$, the current was maintained, resulting in a total energy dissipation of $4.4 \mathrm{~J}$. As a result, the device exploded, leading to a failure to open circuit. No decapsulation was necessary, and Fig. 13 directly presents the exposed die after destruction of the package. In this figure, spots of evaporated metal are clearly visible on all the surface of the die. The damage may have started in the upper right corner, and then have spread across the surface of the device.

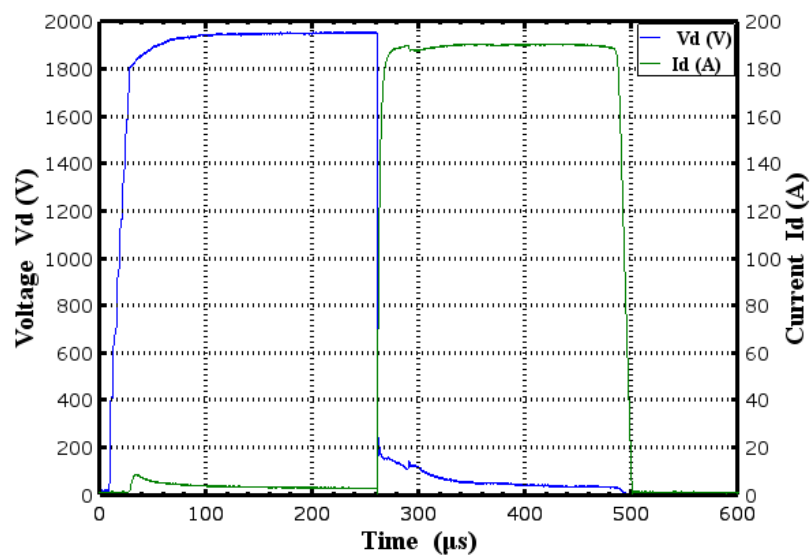

Fig. 12. Measured reverse voltage and current across the diode under avalanche conditions. $\mathrm{Tc}=25^{\circ} \mathrm{C} ; \mathrm{tav}=240 \mu \mathrm{s}$; Etot $=4.4 \mathrm{~J}$; $\mathrm{V}_{\mathrm{BR}}=1800 \mathrm{~V}$. 


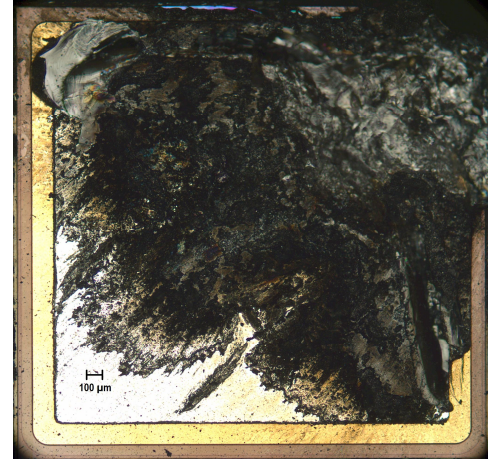

Fig. 13. Damaged of SiC Schottky die caused by maintaining the current after the failure of the device. $\mathrm{tav}_{\mathrm{av}}=240 \mu \mathrm{s} ; \mathrm{E}_{\mathrm{tot}}=4.4 \mathrm{~J}$; $\mathrm{V}_{\mathrm{BR}}=1800 \mathrm{~V}$.

\section{Discussion}

The experimental results have shown that the critical energy, which is the necessary amount of energy to destroy the chip, remained almost constant for all tests (on average $0.877 \mathrm{~J})$. Because of the large experimental scattering $(+/-40 \%)$, this hypothesis of a constant critical energy is not visible from Fig. 4. It is more obvious from Fig. 7, as the average power clearly follows the trend line $\mathrm{P}=0.877 / \mathrm{t}$. This constant energy is only valid for short pulses (less than $300 \mu \mathrm{s}$, where adiabatic conditions can be assumed in the die. This is not true for longer pulses, as some of the energy propagates out of the die (in its cooling system). For example, the critical energy obtained for durations of $1 \mathrm{~ms}$ and more (not presented here for the sake of brevity) result in critical energies of several joules. However, such long pulses were achieved by severely limiting the current during avalanche to a fraction of the rated current of the diode (less than $2 \mathrm{~A}$ for a 20 A diode). In real cases, short pulses conditions seem more representative, as avalanche would occur at a higher current level.

The breakdown voltages are found to be much higher than the rated voltage of the diodes $(1600-1830 \mathrm{~V}$ for $1200 \mathrm{~V}$-rated devices). No correlation could be found between the actual breakdown voltage of a diode and its critical energy.

Moreover, in the results of Section 3, it is shown that SiC Schottky diodes usually fail as a short circuit. Essentially, the failure causes a localized point with a high leakage current. Depending on the conditions of the tests, the damage may be more or less severe. In fact, most failures have been observed at the corner where the electrical field intensity is greatest (see Fig. 9, 11). However, if the current is not interrupted or limited during the avalanche breakdown, the damage will spread, which may destroy the epoxy package and result in an open circuit as shown in Fig. 13. This later failure mechanism correspond to realistic conditions, as no protection system would block the current after failure of the diode. Failure to open circuit, due to explosion of the case, is therefore to be expected if the diode experiences avalanche and dissipates more than a few hundred of millijoules.

\section{Conclusion}

Commercially available 1200V/20A SiC Schottky diodes were tested for an avalanche operation. The analysis of this paper reveals that the avalanche is localized in a small area of the die, resulting in very high power dissipation, and very high temperature (sufficient to create a hole in the $\mathrm{SiC}$ die). A critical energy of $0.877 \mathrm{~J}$ is found, albeit with large dispersion $(+/-40 \%$ from one device to another). If a large current is maintained through the diode after its failure, the corresponding power dissipation exceeds the package capability, and an explosive destruction happens, destroying the interconnections, and resulting in an open circuit.

\section{Reference}

[1] E.Mayerhoff, "Increase Reliability by Using Avalanche Diode", High voltage connection, 2006. Available on: http://www.highvoltageconnection.com/articles/avalanchediodes.htm.

[2] J. Hilsenbeck, M. Treu, R. Rupp, D. Peters, R. Elpelt, "Avalanche Capability of Unipolar SiC Diodes: A Feature for Ruggedness and Reliability Improvement", Materials Science Forum, Vols. 615-617, pp. 659-662, 2009.

[3] A. Fayyaz, L. Yang, M. Riccio, A. Castellazzi, A. Irace, "Single pulse avalanche robustness and repetitive stress ageing of $\mathrm{SiC}$ power MOSFETs", Microelectronics Reliability, Volume 54, Issues 9-10, September-October 2014, Pages 2185-2190.

[4] P. Alexakis et al., "Analysis of power device failure under avalanche mode Conduction," 2015 9th International Conference on Power Electronics and ECCE Asia (ICPE-ECCE Asia), Seoul, 2015, pp. 1833-1839.

[5] H. Zhang, R. Kang, M. Luo and M. Pecht, "Precursor parameter identification for power supply prognostics and health management," Reliability, Maintainability and Safety, 2009. ICRMS 2009. 8th International Conference on, Chengdu, 2009, pp. 883-887.

[6] J. S. George, R. Koga, R. M. Moision and A. Arroyo, "Single Event Burnout Observed in Schottky Diodes," 2013 IEEE Radiation Effects Data Workshop (REDW), San Francisco, CA, 2013, pp. 1-8.

[7] D. Othman et al., "Robustness of $1.2 \mathrm{kV}$ SiC MOSFET devices", Microelectronics Reliability, Volume 53, Issues 9-11, September-November 2013.

[8] JEDEC, "Single Pulse Unclamped Inductive Switching (UIS) Avalanche Test Method", JEDEC STANDARD, JESD245, August 1990.

[9] S. Murali and N. Srikanth, "Acid Decapsulation of Epoxy Molded IC Packages With Copper Wire Bonds," in IEEE Transactions on Electronics Packaging Manufacturing, vol. 29, no. 3, pp. 179-183, July 2006.

[10] R. Raghunathan, B.J. Baliga, "Temperature dependence of hole impact ionization coefficients in $4 \mathrm{H}$ and $6 \mathrm{H}-\mathrm{SiC}$ ", SolidState Electronics, Volume 43, Issue 2, February 1999. 